\title{
Hermenêutica e Ciências Naturais: Introdução
}

\section{Hermeneutics and Natural Science: Introduction}

\author{
Robert P. Crease \\ tradução Rogério Tolfo
}

Uma das curiosas peculiaridades do desenvolvimento do pensamento continental do séc. XX é sua omissão da investigação das ciências naturais. É verdade que a literatura ientífica tenta seriamente adotar a atitude de um objetivo loquaz em um modo que, aparentemente, recusa uma posição segura para uma filosofia que concede prioridade para a experiência vivida.

A filosofia analítica da ciência compreendeu este aspecto ao pé da letra, e desenvolveu-se à custa da incorporação dos elementos da cultura e da história. Filósofos analíticos da ciência consideraram que seu trabalho era formalizar os métodos das ciências naturais, dirigindo seus interesses para além de processos de descoberta e de outras áreas em que fatores sociais, culturais e pessoais poderiam tornar-se decisivos. No entanto, o conhecimento científico, como todo conhecimento, implica uma descoberta (o que é dito) de algo por alguém. Este conhecimento lida com significados que são entes sociais, incorporados na linguagem, alterados ou consumados na experiência, e transmitidos na prática (praxes) do laboratório e na literatura e cultura científica. É atraente, mas um erro, considerar tais significados como formas a-históricas ou "tipos naturais" que tem uma origem transcendente, talvez transcendental. De outro lado, seria igualmente um erro reivindicar que os resultados da ciência são arbitrários ou meros artefatos do discurso; a ciência tem um espaço histórico, um "aqui e agora", com sua referência para um autêntico juiz e testemunho (histórico). A filosofia hermenêutica fornece a fundação filosófica para reintroduzir história e cultura na filosofia das ciências naturais.

Os primeiros fenomenologistas estavam perspicazmente conscientes do papel que a filosofia hermenêutica poderia desempenhar na compreensão da ciência. Husserl tinha uma profunda consideração pela matemática e pela ciência natural; como Patrick Heelan entre outros acentuaram, a objeção de Husserl não foi com a própria ciência, mas com a pretensão galileana de que a ontologia da natureza poderia ser proporcionada apenas pela matemática, omitindo o mundo da vida ${ }^{1}$. Esse é o motivo pelo qual Heidegger, em Ser e Tempo, insiste em qualificar o conhecimento teorético como um modo fundado do Ser-no-

1 Para um conjunto de referências da filosofia da ciência de Husserl por Heelan (e outros), ver Robert Crease, The Play of Nature: Experimentation as Performance (Bloomington: University of Indiana Press, 1993), p. 191 fn.12. 
-mundo, interpretado não meramente como um auxílio para a descoberta, mas como um modo especial e especializado de acesso ao próprio real. Para ambos, Husserl e Heidegger, este desenvolvimento galileano não foi somente um assunto disciplinar, mas uma manifestação de uma crise histórica que eles atribuíram ao papel hegemônico da teoria na arbitragem do sentido, à obliteração do papel dos temas humanos incorporados na constituição do conhecimento, e a suposição implícita, característica da modernidade, de que as ciências naturais fornecem o modelo privilegiado para a investigação humana. Dado a vasta influência da ciência moderna, se presumiria que a exploração sistemática da natureza, a prática e os efeitos das ciências naturais seriam o maior ímpeto do pensamento Continental contemporâneo. Isto não ocorreu, por razões que também são amplamente históricas. A hermenêutica originada na interpretação de textos sagrados e fontes históricas, enraizada nas humanidades e devotada à interpretação de textos e fontes culturais, se desenvolveu por um longo tempo sem referência à dimensão explicativa da ciência natural; a filosofia positivista, entretanto, defendeu as ciências naturais desinteressadas de outros esforços humanos de modo a incorporar uma forma de racionalidade superior. Mesmo quando, pelas mãos de Heidegger e Gadamer, a hermenêutica era expressa em sua relação não somente em campos como arte, lei, história e literatura, mas no escopo integral do compromisso humano com o mundo, filósofos treinados hermeneuticamente reagiram à hegemonia do positivismo dizendo para os cientistas naturais e seus defensores filosóficos: "Não toque nas ciências humanas!" - por meio disso implicitamente sancionando o autorretrato positivista das ciências naturais. Em seu artigo abaixo, Don Ihde caracteriza a situação como a "H/P [hermenêutica-positivista] binária," em que cada pólo pareceu ceder território ao outro, embora o pólo hermenêutico tenha sido reativo. Pensadores hermenêutico-fenomenológicos que seguiram Husserl e Heidegger se inclinaram a interpretar a ciência natural como pesquisa para a teoria e, conseqüentemente, como abstrata e derivada em relação ao mundo da vida. Sendo assim, Gadamer e outros reivindicaram que, em tal caso, não haveria possibilidade de uma hermenêutica das ciências naturais, e certamente um modo tradicional de caracterizar a diferença entre as ciências humanas e naturais implicava se os métodos hermenêuticos eram ou não explicitamente usados ou reconhecidos. Enquanto um número de propostas críticas foi levantado para explorar o pólo positivista, do qual o resultado foi enfraquecer sua pretensão para a autonomia, o isolamento e uma forma privilegiada de racionalidade - realizada por Kuhn inicialmente e em seguida pelos adeptos do "programa forte" da sociologia da ciência - houve uma pequena tentativa para comprometer o outro lado da situa- 
ção binária, partindo do pólo hermenêutico inexplorado como um recurso potencial. Portanto, embora expondo o ponto fraco da compreensão da ciência de inspiração positivista, essa fragilidade não foi compensada, como deveria, por uma apreciação profunda de todas as dimensões hermenêuticas das ciências naturais.

Poucos pensadores resistiram ao ponto de vista tradicional - mais notadamente Paul Ricoeur, que foi inflexível em sua insistência que a hermenêutica não é um método, mas uma filosofia. Poucos filósofos profissionais continentalmente treinados tanto com formação hermenêutico-fenomenológica, quanto com formação científica (tais como Heelan, Ihde, Theodore Kisiel, Joseph Kockelmans) tem interpretado o trabalho de Heidegger, Merleau- Ponty, Gadamer e outros, do mesmo modo em que tem vinculado uma reavaliação positiva das práticas das ciências naturais. Poucos cientistas profissionais com uma formação erudita em filosofia hermenêutico-fenomenológica (entre os quais está Martin Eger) começaram a fazer o mesmo. Diversos filósofos da ciência atual (mainstream) estão utilizando discernimentos (insights) efetivamente e perceptivelmente hermenêuticos (Joseph Rouse), enquanto muitos eruditos sociologicamente treinados, que se expressam com a terminologia e freqüentemente com as suposições da filosofia analítica, revelam em seus trabalhos uma profunda apreciação pelo discernimento (insight) hermenêutico a respeito da natureza do conhecimento situado historicamente (Harry Collins, Bruno Latour, Andrew Pickering, Simon Schaffer, Steve Shapin e influenciados pelo construtivismo social). Estas iniciativas manifestam a redescoberta de que todo discurso é situado culturalmente e historicamente. Passaram-se os dias em que poderia ser seriamente debatido se uma perspectiva hermenêutica para as ciências naturais existe ${ }^{2}$. O desafio hoje permanece em compreender mais explicitamente a dimensão hermenêutica das ciências naturais em termos de uma cobertura (overarching) hermenêutica de todo conhecimento.

Os artigos sobre essa questão estão entre aqueles apresentados no quarto encontro anual da International Society for Hermeneutics and Science (ISHS), reunido em 1996 na Universidade do Estado de Nova Iorque em Stony Brook. A ISHS teve início em 1993, tanto como iniciativa Europeia (seus dois primeiros encontros ocorreram na Hungria, o terceiro nos Países Baixos) quanto devido ao resultado do renascimento do interesse em filosofia hermenêutico-fenomenológica depois do fim do domínio Soviético dos círculos acadêmicos

2 A última troca de ideias séria neste debate foi talvez Gyorgy Marcus, "Why is There No Hermeneutics of the Natural Science? Some Preliminary Theses". Science in Context 1987, pp. 5-51, seguida por Patrick A. Heelan, "Yes! There is a Hermeneutics of Natural Science: Rejoinder to Marcus", Science in Context 3, 1989, pp.477- 488. 
na Europa Oriental e Central. A ISHS, composta originalmente por estudiosos Europeus, rapidamente auxiliou a coordenar e pôr em evidência os interesses de diversos pesquisadores dos Estados Unidos que haviam trabalhado de modo relativamente independente. Seus membros encontraram uma ampla variedade de questões nas ciências naturais a serem clara e rapidamente acessíveis para a investigação ermenêutica, tais como: como fazer indivíduos ou grupos alcançarem acordos em certas situações problemáticas nas quais eles mesmos se encontram delineados junto a recursos conceituais e práticos disponíveis que estruturam aquela situação? Como o sentido surge fora das situações de laboratório? O que é a fenomenologia da prática (praxis) científica perceptiva? Os artigos apresentados desdobraram-se a partir de discussões gerais sobre a natureza e o desenvolvimento da hermenêutica, as aplicações da hermenêutica para diferentes áreas da ciência, de debates sobre o papel da hermenêutica na ciência, do passado dos pensadores hermenêuticos acerca da ciência e de direções futuras na investigação hermenêutica na ciência ${ }^{3}$.

Embora seja incorreto caracterizar as perspectivas hermenêuticas sobre a ciência como constituindo um "programa", dada à importância e à previsibilidade das diversas perspectivas que emergiram é, contudo, possível pontuar uma constelação de ideias orientadoras.

A primeira deve ser chamada a prioridade do sentido sobre a técnica. A ciência é inteiramente descaracterizada enquanto consistindo exclusivamente de atividade prática (praxes), da aplicação de técnicas ou métodos de cálculo, porque dados, resultados e eventos de laboratório chegam ao ente por interpretação, e são descritos equivocadamente se a interpretação é insuficientemente realizada. Esta ideia, naturalmente, corresponde a uma crítica à filosofia positivista e à filosofia da ciência convencional. Pois um básico discernimento hermenêutico afirma que a geração do sentido, em ciência como em outras atividades humanas, não procede exclusivamente pelo movimento da parte para o todo, mas por um processo em que os fenômenos são projetados por meio de uma estrutura de sentido já existente, dos quais as suposições são ao menos parcialmente trazidas para a questão, e por esta ação decididamente examinadas e refinadas no contínuo processo de interpretação. Quando alguém age interpretativamente, pode levar para a situação algo que foi historicamente e culturalmente transmitido, especialmente quando alguém opta por agir dentro de uma atividade original com a finalidade de alcançar uma conexão muito profunda e

3 As Atas do Terceiro Encontro Anual da ISHS estão em: M. Feher, O. Kiss e L. Ropolyi, eds.: Hermeneutics and Science (Dordrecht: Kluwer, forthcoming). 
muito rica com o mundo. Deste modo, a natureza e o âmbito das práticas interpretativas é um assunto da pesquisa hermenêutica nas ciências.

Uma segunda ideia orientadora deve ser chamada a primazia do prático sobre o teórico. A estrutura de sentido em termos dos quais os fenômenos são interpretados não é compreendida somente a partir dos instrumentos, dos textos e das ideias, mas envolve um compromisso com o mundo, determinado cultural e historicamente, que é anterior a separação sujeito e objeto. Kisiel aponta que o relacionamento hermenêutico do Heidegger inicial é simplesmente "a compreensão da familiaridade que surge da existência pessoal com outros entre coisas no mundo". Kisiel continua: "o ponto atrás da identificação do Dasein com sua compreensão do ser é simplesmente que o hábito hermenêutico/interpretativo encontra-se no âmago do ser humano. Este hábito ou ethos está primordialmente presente em todos os nossos compromissos proto-práticos que definem 'o modo em que as coisas são"'.. No termo grego 'ético', que os filósofos hermenêuticos buscam reviver o âmago do bem viver, ser completamente humano, ser ontologicamente 'autêntico', reside não na virtude teórica, mas na virtude prática, a 'arte' ( $\tau \dot{\varepsilon} \chi v \eta)$ de fazer bem no mundo do trabalho e o 'fato' ( $\varphi \rho o ́ v \eta \sigma ı \varsigma)$ de agir bem na política."

Uma terceira ideia orientadora deve ser chamada de prioridade da situação sobre a formalização abstrata. A verdade sempre envolve uma revelação de algo para alguém em um contexto cultural e histórico. Nem mesmo o conhecimento científico pode transcender completamente estes engajamentos determinados cultural e historicamente, deixando-os para trás como se o conhecimento científico consistisse de abstrações consideradas de nenhum lugar em particular. A particularidade do fenômeno descoberto pela ciência é freqüentemente ocultada pelo fato de que tais fenômenos podem mostrar a si mesmos em diferentes contextos culturais e históricos desde que o ambiente (laboratório) científico esteja correto. Esta generalidade pode dar a ilusão de conhecimento não incorporado. Uma vez que o trabalho científico principia em um envolvimento já existente com, e da compreensão de, uma situação concreta, ele nunca deixa a concretude para trás; de modo algum a compreensão escapa do círculo hermenêutico. Em situações vagas, enigmáticas ou paradoxais, a consecução do sentido não é uma transcendência ou uma abstração de, mas um aprofundamento e extensão das relações de alguém como mundo. A compreensão hermenêutica não alcança a correção de ideias falsas, mas a extensão da linguagem refletindo uma extensão do conceito.

Os artigos aqui selecionados, do mais recente encontro do ISHS e incluindo principalmente pesquisadores dos Estados Unidos, aderem a três grupos: um grupo 
cujo foco está em recordar e aplicar recursos existentes da fenomenologia hermenêutica, um grupo cujo foco é articular a distinção da abordagem hermenêutica frente a outras (tais como a filosofia da ciência atual, os estudos culturais e o construtivismo social), e um grupo que procura forjar novas direções e ferramentas.

Em "Por que uma Filosofia Hermenêutica das Ciências Naturais?" Patrick A. Heelan expõe os argumentos gerais para uma abordagem hermenêutica para a ciência, transcurso no qual mostra como as três ideias orientadoras acima mencionadas estão fundadas na obra de pensadores hermenêuticos canônicos. Uma das principais contribuições de Heelan para a fenomenologia, elaborada mais extensivamente em Espaço-Percepção e a Filosofia da Ciência, é sua observação de que a percepção não é um ato automático de um sujeito independente (isto é, independente da cultura e da determinação), mas é hermenêutico à medida que é um ato interpretativo guiado pelo engajamento humano com o percebido (isto é, através do mundo) ${ }^{4}$. A principal contribuição de Heelan especificamente para a fenomenologia da ciência é sua observação (que extraiu da descrição do Dasein como ser-nomundo de Heidegger e da análise da experiência mediada pela instrumentalidade) de que o mundo da vida da cultura contemporânea já e inevitavelmente envolve instrumentos científicos e fenômenos científicos que compartilham a mesma estrutura geral tal qual outro fenômeno do mundo da vida. A observação de Heelan explica não apenas porque os cientistas "são realistas no laboratório", tratando instintivamente o fenômeno que eles encontram aí como cidadãos do mundo da vida naturalizado, mas refuta os argumentos daqueles que, acentuando o prático, o lado aparentemente construtivista social da ciência, sustentam que a perceptibilidade recai apenas sobre instrumentos e não sobre entes descritos teoricamente que os movem ${ }^{5}$. Para Heelan tampouco a teoria pode ser concebida como meramente instrumental, nem como pintando entes que existem separados do mundo da vida; teoria é impregnada de prática (práxis-laden), sempre conectada com equipamentos que cumprem alguma função cultural. Mesmo o processo de "medição", distante de constituir-se de mera observação passiva, é apenas possível dentro de uma atividade culturalmente projetada de preparação, apresentação e realização estruturada hermeneuticamente. "A ciência e a filosofia da ciência", indica Heelan, são propensas a esquecer "a necessária conexão da teoria com uma prática impregnada (práxis-laden) de explicações culturais", adicionando que a

4 Patrick A. Heelan, Space-Peception and the Philosophy of Science (Berkeley: University of California Press, 1983). E sou grato a Patrick A. Heelan por seus comentários sobre esta introdução.

5 Uma discussão mais extensa dos argumentos e contra-argumentos pode ser encontrada em Crease, Play of Nature. 
"filosofia hermenêutica está particularmente interessada com os perigos do esquecimento deste nexo". O esquecimento deste nexo é o principal obstáculo do emaranhado número de questões chaves não resolvidas na filosofia da ciência, incluindo os mistérios e paradoxos associados com o fenômeno e a teoria do quantum. Heelan (ele mesmo um físico) desenvolveu mais esta ideia alhures; que ele dedica alguma discussão ao Paradoxo do Gato de Schrödinger ${ }^{6}$. Uma compreensão hermenêutica da ciência, ele alega, deve também restabelecer um diálogo entre a comunidade científica e seus clientes, assistentes, interpretes acadêmicos e o público amplo, o colapso destas está manifesto em um número de eventos contemporâneos que incluem a assim chamada "guerra da ciência".

Joseph Kockelmans, em "Sobre a Natureza da Ciência Natural Moderna", foca mais estreitamente em uma arena específica na qual o trabalho científico está subordinado a estruturas de sentido pré-existentes. Kockelmans é um dos iniciadores do estudo hermenêutico-fenomenológico da ciência e recentemente resumiu o seu trabalho em Ideas for a Hermeneutic Phenomenology of the Natural Sciences ${ }^{7}$. Neste artigo ele mostra como a prioridade da interpretação sobre a técnica é ilustrada na peculiaridade em que cada uma das diversas figuras chave no começar da ciência moderna "projeta fenômenos observados sobre estruturas de sentido que foram desenvolvidas independentemente de suas próprias observações". A compreensão que Kepler tem de Copérnico e da existência de dados astronômicos em termos de uma mistura de ideias religiosas e pitagóricas-platônicas, a compreensão de Galileu de suas observações à luz da filosofia aristotélica e a confiança de Newton nas suposições de seus predecessores ilustram como, na teorização científica, há sempre "um número de suposições ou pré-julgamentos, na base dos quais os fenômenos naturais são interpretados em harmonia com o que na fenomenologia hermenêutica é denominado de tematização objetificante". Como consequência, "todas as formas de descrição, explicação e compreensão são sofisticadas formas de interpretação", o que implica, por sua vez, que declarações científicas podem "exprimir algo que é verdadeiro sem exaustiva veracidade sobre o que é”.

Um exemplo de hermenêutica aplicada é "Compreensão Sustentável," de Bart Gremmen e Jossete Jacobs, da Universidade Agrícola de Wageningen na Holanda. Estes autores esforçam-se para mostrar como deve ser possível, em

6 Patrick A. Heelan, "Hermeneutique de La Science Experimentale: La Mecanique Quantique et lês Sciences Sociales", in Hermeneutique: sciences et textes (Paris: Presses Universitaire de France, 1997); or "Quantum Mechanics and the Social Sciences: After Hermeneutics", in Science \& Educacion, 4 (1995), pp. 127-136.

7 Dorcrecht: Kluwer, 1993. 
situações envolvendo diferentes concepções de sustentabilidade, por diferentes setores econômicos, evitar ter que escolher entre concepções mutuamente destrutivas e competidoras recorrendo a um diálogo como o gadameriano que se movimenta entre um conceito vago e geral de sustentabilidade e a situação local. É impossível explicar este tipo de resolução de conflito da perspectiva atual que assume que esses tipos de conflito incluem, essencialmente, competidores que trazem à mesa consciência e princípios completamente formados, estruturas de pensamento e crenças. Uma abordagem hermenêutica, em contraste, vê as partes como partindo de diferentes situações existenciais e como perpetuamente abertas a uma nova compreensão delas mesmas e de sua situação para o diálogo com outras partes; pensá-las como competidoras falsifica a imagem de partida. Outra interessante característica deste artigo é o modo que usa a abordagem hermenêutica para criticar posições que tratam ecossistemas como construções sociais e que tratam resoluções de conflito entre setores competitivos como negociações que obstruem o diálogo: "differend," nos termos de Lyotard, mais do que controverso.

Um segundo conjunto de artigos enfoca explicações sobre as diferenças entre a abordagem hermenêutica com a ciência e outros relatos de abordagens. Em "Uma Hermenêutica das Ciências Naturais? O Debate Atualizado", Kisiel aponta falhas nos argumentos daqueles que tentam negar a possibilidade de tal hermenêutica. Gadamer é um; mas citando Hermann Von Helmholtz, uma das fontes chave de Gadamer, Kisiel observa que a racionalidade por aquele reivindicada não é tão clara como Gadamer compreenderia ser. Kisiel em seguida dedica-se ao argumento de Gyorgy Markus, que sustenta, muito dramaticamente, que "as ciências naturais, na prática, parecem não ter necessidade nenhuma de uma hermenêutica"; a "hermenêutica cultural" da ciência que ele então propõe, de fato, inclui um papel substancial para uma hermenêutica prática heideggeriana. Porém, como Heelan convincentemente demonstrou, uma hermenêutica de estilo heideggeriana está precisamente envolvida naquelas áreas das quais Markus a exclui. Rouse fez dois movimentos exemplares: ele resistiu à desnaturação da hermenêutica prática Heideggeriana na direção da hermenêutica teórica de Quineana (esboçando pesadamente em Foucault no processo), e resistiu ao empreendimento de usar diferentes e alegados papéis à hermenêutica como um modo de distinção entre ciências humanas e naturais (a questão da "dupla hermenêutica"). Embora Rouse tenha continuado a executar uma perspectiva hermenêutica para a ciência, ele parou de descrever o que fazia com esta palavra - e também com referência a tradição que segue junto - talvez pretendendo 
uma terminologia mais familiar à filosofia da ciência atual (mainstream) ${ }^{8}$.

Em um trio de ensaios significativos, Martin Eger sugeriu que a filosofia hermenêutica inclui uma alternativa e uma crítica ao construtivismo". Em "Realizações da Abordagem Hermenêutico-Fenomenológica para a Ciência Natural: Uma Comparação com a Sociologia Construtivista," ele elabora mais explicitamente seu argumento contra a posição social construtivista. O construtivismo social envolve o ponto de vista de que a ciência pode reivindicar conhecer apenas os produtos da construção humana e nenhuma realidade independente deste processo. $\mathrm{O}$ construtivismo social é freqüentemente confundido com o programa dos estudos sociais do conhecimento que visa destacar os significados sociais implícitos na ciência e configurar sua prática, que por este alcance é hermenêutica ${ }^{10}$. O que é incômodo sobre o construtivismo, diz Eger, é a arrogante convicção que exibe o seu resultado, e ele está interessado em expor a pouca profundidade da posição que identifica os resultados da ciência com meros artefatos do discurso de seus praticantes ${ }^{11}$.

Eger nota que o termo chave no arsenal do construtivismo social é "negociação", entendido para significar o processo no qual os indivíduos com interesses opostos apaziguam conflitos por negócios fora destes interesses. Citando Collins, Eger aponta que a negociação “é caracterizada como 'afunilar em' interesses sociais, desviando-os para tácitas negociações não científicas e usando-

8 Ver o mais recente trabalho de Rouse, Engaging Science: How to Understand its Practices Philosophically (Ithaca, NY: Cornell University Press, 1996).

9"Hermeneutics and Science Educacion: An Introduction", Science and Education 1 (1992): pp. 337-348; "Hermeneutics as na Approach to Science", Part I, Science \& Education 2 (1993): pp. 1-29; Part II, Science \& Education 2 (1993): pp. 303-328. Ver também a edição especial deste jornal dedicada as discussões dos artigos de Eger: Science \& Education 4:2 (1995).

10 Tal equívoco é frequentemente feito pelos detratores da hermenêutica assim como do social construtivismo; o título do famoso embuste de Alan Sokal/analisando (exposé) principalmente escritos de autores do construtivismo social sobre a ciência foi "Transgressing the Boundaries: Toward a Transfomative Hermeneutics of Quantum Gravity", Social Text pp. 46-47 (1996): 217-252. Respostas para Sokal são encontradas em Andrew Ross, Ed., Science Wars (Durham, NC: Duke University Press, 1996, and Rouse 1996 pp. 9-12; 15-21, 237-259).

11 Esta é a posição que muitos praticantes do social construtivismo frequentemente pronunciam, ao menos, como eles defendem. Em um trabalho sobre a ciência moderna inicial, Steven Shapin e Simon Schaffer escrevem que "a objetividade da questão experimental de fato foi um artefato de certas formas de discurso e certos modos da solidariedade social"; questões de fato, eles reivindicam, são apenas "convenções" resultantes de "negociações entre experimentadores" (Leviatan and the Air-Pump: Hobbes, Boyle and the Experimental Life, Princeton: Princeton University Press, 1985). Collins e Trevor Pinch escrevem que "cientistas na frente de pesquisa não podem determinar seus desacordos pela melhor experimentação, maior conhecimento, teorias mais avançadas ou pensamento mais claro" (The Golem: What Everyone Should Know About Science, New York: Cambridge University Press, 1993). Enquanto ambos os grupos de autores estão falando do modo que as representações científicas são constituídas, elas não necessitam necessariamente ser interpretadas como tratando da natureza do objeto científico que é assim representado, embora seja isto o que frequentemente eles dizem. 
-os para "manufaturar conhecimento certificado" e o efeito seria tratar juntos "diferentes tipos de atividade sob a mesma rubrica e rotular a todos de "social".

Esta é uma ficção metodológica que, por mais que conveniente, substitui o modo de nosso reconhecimento e nossa percepção da rica complexidade do processo científico; em primeiro lugar, isto requer "a combinação nivelada do processo de produção envolvido em um experimento [com] a performance do experimento". Para ilustrar, Eger reexamina um caso de estudo favorito de Pinch e Collins de um experimento pelo Laboratório Nacional de Brookhaven em que o físico Raymond Davis primeiro detectou a existência de neutrinos solar. Em suas análises, os autores classificaram como "negociação" tanto a diligência de Davi para pedir permissão à Comissão de energia Nuclear por fundos a fim de conduzir o experimento, quanto à incorporação de Davi de melhorias em seu aparelhamento experimental. "Colocar os dois sob o mesmo tópico não é apenas bruto," escreve Eger, "é um obscurecimento injustificável da imagem e uma mistificação da ciência". Para ele, o entrelaçamento de instrumentos, práticas e pré-concepções é tratado muito melhor pela abordagem hermenêutica do que pelo estilo de expor dos construtivistas.

O trabalho de Don Ihde, especialmente em Instrumental Realism, delineia os interesses fenomenológicos tradicionais na percepção e no corpo para articular a materialidade do instrumento no processo de produzir legíveis, embora objetos perceptivos no laboratório ${ }^{12}$. Em seu artigo "Hermenêutica Objetificada/Tecnoconstruções," Ihde decididamente elaborou este trabalho conectando-o com alguns dos discernimentos (insights) de Bruno Latour. "'A natureza' é preparada no laboratório, se manifesta como inscriçãovisual que pode ser 'interpretada' através da percepção treinada cientificamente". Enquanto algumas manifestações visuais tem o que Ihde denomina "um vestígio de realismo isomórfico" em que elas retêm uma referência disposta a um objeto discreto mesmo que em diferentes escalas (raio X de parte do corpo, Modelo DNA para molécula de ácido), outros produtos de laboratório envolvem muitos estratos complexos de construtividade. Estas “tecnoconstruções," como ele as denomina, não são textos (por isso, revelando seu sentido apenas na leitura), nem imagens (intuídas apenas pela visão); preferivelmente, são híbridos "vistos-lidos" que combinam "qualidades de comportamento perceptivo com qualidades 'textuais' inscritas através dos quais o resultado científico - conhecimento - é produzido". Realmente, aponta Ihde, o montante de informação contida na manifestação pode aumentar com o nível da tecnoconstrução, ilustrando este ponto com a ajuda

12 Bloomington: Indiana University Press, 1991. 
do que ele chama "Medição Total da Terra". O trabalho de Ihde revela "uma profunda epistemologia hermenêutica dirigida à ciência contemporânea em sua genuína essência" e assenta o fundamento da prática experimental do laboratório e especialmente de práticas imaginadas em uma apreciação muito mais sofisticada - um fundamento superior que seria alcançado pelo tratamento "das práticas representacionais da gama total dos cientistas", na frase hiperbólica de Fuller, como "um domínio corrupto de objetos privilegiados"13. A contribuição de Ihde também contém implicações significantes para a própria hermenêutica, à medida que ajuda a liberar a hermenêutica de sua preocupação com a textualidade.

$\mathrm{O}$ artigo de Eugene T. Gendlin "A Ordem Responsiva: Um novo Empirismo" não é apenas escrito em um estilo distinto, mas atualmente realiza mudanças em alguns rumos além do particular apuro, mostrado pela hermenêutica, em que a filosofia moderna tornou-se uma armadilha. $\mathrm{O}$ apuro implica ter que escolher entre: de um lado, a suposição que em algum lugar na natureza encontra-se um fixo ocultamento, uma ordem estável, e de outro lado o ponto de vista de que toda ordem é imposta de fora e que qualquer padrão que vemos na natureza representa meramente um artefato de formas, convenções, história, tradições e interesses com os quais a natureza é abordada. O defeito do precedente, que envolve a hipótese que, diz Gendlin, a filosofia natural medieval e Newtoniana são passos ascendentes no progresso para "a verdade", foi completamente explorado inicialmente com Kuhn e continuado pelos construtivistas sociais. Contudo, aceitar o ponto de vista alternativo é imaginar a natureza como sendo simplesmente uma ideia cultural-histórica, o que torna a pesquisa incapaz de acessar qualquer coisa exceto construções humanas.

O trabalho de Gendlin nos permite começar a desenvolver termos com os quais é possível pensar além da dupla negação implicada na recusa de ambas alternativas. Muitas vezes, mostra Gendlin, encontramos numerosos tipos de ordem em que recuperamos, conforme uma situação, novos significados e efeitos que não resultam da situação de que nós os trouxemos. Como Wittgenstein mostrou, por exemplo, o uso de uma palavra em uma situação não usual pode permitir que tal palavra significasse algo bastante preciso que ninguém tenha ainda declarado. Gendlin chama isto uma ordem responsiva, pela qual ele compreende não alguma coisa a que nos reportamos, mas que já estamos no interior. Mesmo declarando que a natureza tem um tipo de ordem ele mantém o discernimento (insight) de que as formas, convenções e interesses estão sempre envolvidos em nossas lidas com a natureza, sem que imponham arbitrariedade.

13Steve Fuller, “Back to Descartes? The Very Idea!’ Social Studies of Science 19 (1989): 357-360 at p. 358. 
O que recuperamos de nossas ocupações não é arbitrário porque a natureza está realmente comprometida, mas diferentemente, por diferentes atividades. "Apesar de que o empírico é responsivo para, não separável de nossos procedimentos e conceitos, seus papéis são independentes deles em alguns aspectos especificáveis". Especificando estes efeitos e suas implicações, inteiramente, em seu artigo, Gendlin desenvolve o que ele denomina um novo empirismo, que não é ingênuo.

Como o artigo sugere sobre esta questão, a abordagem hermenêutica dirige-se e pode ajudar a resolver inúmeras questões perplexas na filosofia da ciência, incluindo a natureza e o papel das dimensões sociais da ciência, o peculiar status das técnicas imaginadas e os "mistérios" da mecânica quântica. Assim como Eger, Heelan e Ihde insistem, ainda que em modos diferentes, que o desenvolvimento de uma abordagem hermenêutica para a ciência tornou-se crescentemente urgente. Uma razão é simplesmente a crescente complexidade da ciência e a necessidade de ferramentas conceituais para a tarefa de compreender coisas como as mudanças integrativas trazidas junto à infraestrutura computacional avançada, redes de conhecimento e fluidez de informações universais que prometem provocar importantes mudanças na vida social. Eger também notou a importância de tratar novamente a questão do sentido sobre e da ciência, para enfrentar as várias crises contemporâneas em educação da ciência bem como na compreensão pública da ciência ${ }^{14}$.

Uma perspectiva hermenêutica sobre a ciência é essencial, também, no momento em que a noção de um livro da natureza ou de estrutura sagrada que organiza e explica o mundo perderam sua força persuasiva. $\mathrm{O}$ desejo de ver a ciência como incluindo uma referência a uma verdade ou campo profundo das essências na natureza - assim como o movimento reativo que afirma que nada há além de nós mesmos e que qualquer descrição que damos da natureza é meramente uma projeção arbitrária de nossos próprios interesses - é remanescente do positivismo do qual a perspectiva hermenêutica pode contribuir para que nos libertemos. Em relação à perspectiva hermenêutica, não se defronta em ter que escolher entre requerer um final, uma verdade oculta de um lado, ou qualificar a verdade um assunto da convenção arbitrária de outro.

Mas para muitos destes autores, desenvolver uma filosofia hermenêutica da ciência é essencial também para o futuro da própria hermenêutica. Para Gendlin, desenvolver o conceito de ordem responsiva é crucial para mover-se além do fim sem saída filosófico em que fomos apanhados. Para Ihde, um relato adequado das coisas como tecno-construções ajuda a libertar a hermenêutica de

14 Eger 1993. 
sua habilidade para compreender o sentido apenas na compreensão de textos. Para Heelan, os elementos que uma abordagem hermenêutica reintegram na filosofia da ciência são essenciais "se a filosofia deve ter a legítima chance de cumprir seu papel como uma reflexão universal para a ciência natural e para toda a ciência (Wissenschaft)".

Daqui a menos de três anos, as figuras chave do cânone hermenêutico (incluindo Heidegger, Wittgenstein, Merleau-Ponty, Ricoeur e Gadamer) se tornarão pensadores do século passado. Estes pensadores, é prudente dizer, não apreciaram suficientemente a significância da hermenêutica para as ciências naturais. Por diversas razões, eles não estavam interessados na filosofia da ciência per se. Alguns (tal como Heidegger) focam em outras questões (a questão do Ser), ciente do interesse apenas quando, e se a filosofia da ciência inclui ou auxilia a elucidar tais questões. Outros (Gadamer) estão interessados na ciência apenas como um fenômeno a ser integrado de volta no restante da vida. Ainda outros, estão interessados mais especificamente nas ciências humanas. Nenhuma destas figuras parece ter compreendido como obstinadamente a ideia de ciência natural enquanto um modelo privilegiado para a investigação humana se sustentaria a despeito de todos os seus trabalhos.

Nenhuma destas figuras parece ter compreendido como o complexo e rico projeto de contextualização das ciências naturais confirmar-se-ia. E compreender a ciência natural é difícil e desgastante para estranhos a ela: enquanto Husserl foi um competente matemático para falar de primeira mão sobre a prática da matemática, nenhum dos pensadores mencionados foi apto para similarmente falar da experiência acerca dos modos em que a ciência natural é uma atividade hermenêutica. Um conjunto amplo de tópicos na hermenêutica das ciências naturais está, portanto, aberto para investigação. Apenas mencionando um dos quais eu escrevo, a hermenêutica está envolvida no processo de experimentação, ou o estágio de uma ação a fim de compreender o presente ainda enigmático. Experimentos são antes de tudo eventos materiais no mundo. Eventos não produzem números - eles não são eles mesmos medidas - mas apenas quando a ação é planejada, preparada e testificada. Um experimento, portanto, tem o caráter de uma performance, e como todas as performances deve ser compreendido como um processo hermenêutico situado historicamente e culturalmente ${ }^{15}$. Desenvolver este e outros tópicos oferece uma oportunidade para levar adiante o trabalho das figuras do cânone hermenêutico em um modo que tornará a própria filosofia hermenêutica mais efetiva e influente.

15 Crease 1993. 


\section{$\{$ Referência Bibliográfica}

COLLINS, Harry M. \& PINCH, Trevor. The Golem: What Everyone Should Know About Science, New York: Cambridge University Press, 1993.

CREASE, Robert. The Play of Nature: Experimentation as Performance (Bloomington: University of Indiana Press, 1993), p. 191 fn.12.

EGER, M. "Hermeneutics and Science Educacion: An Introduction", Science and Education 1 (1992): pp. 337-348.

. "Hermeneutics as na Approach to Science", Part I, Science \& Education 2 (1993): pp. 1-29; Part II, Science \& Education 2 (1993): pp. 303-328.

Science \& Education 4:2 (1995). FEHER, M., KISS, O. \& ROPOLVI, L. Hermeneutics and Science (Dordrecht: Kluwer, forthcoming). Atas do Terceiro Encontro Anual da ISHS.

FULLER, S. "Back to Descartes? The Very Idea!", Social Studies of Science 19 (1989): 357-360 at p. 358.

HEELAN, Patrick A. "Hermeneutique de La Science Experimentale: La Mecanique Quantique et lês Sciences Sociales", in Hermeneutique: sciences et textes (Paris: Presses Universitaire de France, 1997); or "Quantum Mechanics and the Social Sciences: After Hermeneutics", in Science \& Educacion, 4 (1995), pp. 127-136.

. Space-Peception and the Philosophy of Science (Berkeley: University of California Press, 1983).

. "Yes! There is a Hermeneutics of Natural Science: Rejoinder to Marcus", Science in Context 3, 1989, pp.477-488.

IHDE, Don. Instrumental Realism: The Interface between Philosophy of Science and Philosophy of Technology, Bloomington: Indiana University Press, 1991.
KOCKELMANS,J.J.Ideasfor a Hermeneutic Phenomenology of the Natural Sciences, Dorcrecht: Kluwer, 1993.

MARCUS, Gyorgy. "Why is There No Hermeneutics of the Natural Science? Some Preliminary Theses". Science in Context 1987, pp. 5-51.

ROSS, Andrew. Science Wars (Durham, NC: Duke University Press, 1996, and Rouse 1996 pp. 9-12; 1521, 237-259).

ROUSE, J. Engaging Science: How to Understand its Practices Philosophically (Ithaca, NY: Cornell University Press, 1996).

SCHAFFER, S. \& SHAPIN, S. Leviatan and the AirPump: Hobbes, Boyle and the Experimental Life, Princeton: Princeton University Press, 1985.

SOKAL, Alan. "Transgressing the Boundaries: Toward a Transformative Hermeneutics of Quantum Gravity", Social Text pp. 46-47 (1996): 217-252.

\section{Copilação bibliográfica feita pelos editores, a partir das referências indicadas em notas no corpo do texto}

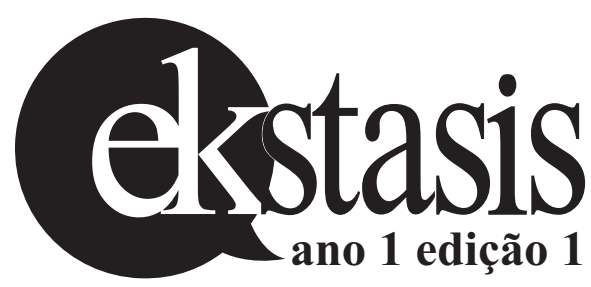

